\title{
In vitro multiplication of rough lemon (Citrus jambhiri Lush.)
}

\author{
Kiran Kour ${ }^{1}$ Bikramjit Singh ${ }^{2}$ \\ ${ }^{I}$ Division of Fruit Science, Sher-e-Kashmir University of Agricultural Sciences \& Technology, Jammu (J\&K)- \\ 180012 , India. \\ ${ }^{2}$ KVK, Gurdaspur, Punjab Agriculture University, Ludhiana, Punjab, India.
}

\begin{abstract}
In vitro multiplication of Rough Lemon (Citrus jambhiri Lush.) was carried out from nodal segments to standardize the protocol for mass multiplication under lab conditions. It was found during experimentation that MS medium supplemented with BAP $(1.5 \mathrm{mg} / \mathrm{L})$ and malt extract $500 \mathrm{mg} / \mathrm{L}$ resulted in maximum culture establishment, number of shoots and length of longest shoot per culture in minimum time during shoot proliferation. The in vitro multiplied shoots could be best rooted in half strength medium supplemented with IBA and NAA $(1.0 \mathrm{mg} / \mathrm{L})$ each with $3 \%$ sucrose as carbohydrate source. In vitro formed plantlets were hardened in potting mixture containing sand, soil and FYM (1:1:1) and highest survival (83.33\%) was achieved after transplantation when rooted plantlet leaves were treated with $50 \%$ glycerol as an antitranspirant.
\end{abstract}

Key words: Citrus jambhiri, Nodal segments, BAP, Malt extract, Shoot proliferation

\section{Introduction}

Citrus is considered as the number one fruit of the world due to its high nutritional value, great production potential and preparation of large number of fruit products from them. Citrus species are cultivated in most tropical and subtropical regions of the world. Rough lemon ( $C$. jambhiri Lush.) is a commonly used rootstock in south Asia and it is an excellent rootstock for warm, humid areas with deep sandy soils. In these environments trees budded on this rootstock grow rapidly, remain productive for longer period and produce high quality fruit (Vij and Kumar, 1990 [1]). Rough lemon being polyembryonic in nature, give rise to several vigorous and virus free nucellar seedlings which are difficult to differentiate from zygotic seedling, and are also difficult to eliminate from zygotic seedlings, which necessitate the application of in vitro micropropagation (Edriss and Burger, 1984 [2]), however, very little work has been carried out on the tissue culture of this plant (Ali and Mirza, 2006[3]).

Rapid and cost effective in vitro methods of reproducing this rootstock would ensure bulk production of true to type and disease free planting material. Hence, the present study was undertaken to standardize the protocol for in vitro multiplication of this commercially important rough lemon rootstock.

\subsection{Plant material}

II. Materials And Methods

Growing shoot tips (5-6 cm long) of Citrus jambhiri were collected from 8-10 year old selected trees from the orchard of Sher-e-Kashmir University of Agricultural Sciences and Technology-Jammu, India.

\subsubsection{Preparation and sterilization of explants}

The expanded leaves were removed and then treated with $10 \%$ solution of detergent Teepol for 10 minutes and then washed thoroughly with distilled water. Explants were surface sterilized in $70 \%$ ethanol for 30 seconds followed by $0.1 \%$ mercuric chloride $\left(\mathrm{HgCl}_{2}\right)$ solution $(\mathrm{w} / \mathrm{v})$ for 8 minutes and then rinsed 3 times with sterile (autoclaved) distilled water.

\subsubsection{Culturing of explants for shoot proliferation}

Nodal explants 0.5-1.0 cm long, were isolated and cultured in Murashige and Skoog (MS:1962) agar medium (Murashige and Skoog, 1962 [4]) supplemented with varying concentration and combinations of cytokinin (BAP), auxin (NAA) and malt extract $500 \mathrm{mg} / 1$ (Table 1) for their shoot multiplication.

\subsubsection{Transfer of proliferated shoots to rooting media}

In vitro proliferated shoots were transferred to rooting media composed of half strength MS medium containing IBA and NAA alone or in combination (Table 2) for rooting. There was no auxin in control. To study the effect of sucrose concentration on in vitro rooting, sucrose (1.5, 3.0 and 4.5 percent) to half strength MS medium was used (Table 3). All these cultures were kept in a condition of 16/8 hours photoperiod at light intensity of 3,000-3,200 lux and at $25+1^{\circ} \mathrm{C}$ constant temperature. 10 cultures in each treatment formed one replication and the experiment was replicated thrice. 


\subsubsection{Hardening of in vitro raised plants}

Complete plantlets with shoot and root systems were removed from culture tubes and residual agar at the root region was removed with tap water. The plantlets were planted in pots filled with different combinations (soil, soil+sand (1:1), soil+sand+FYM (1:1:1) and soil+sand+vermiculite (1:1:1)) of autoclaved hardening mixture (Table 4). The potted plantlets were kept for 2 weeks, covered with clear plastic sheet in the culture room conditions, after which they were transferred to a green house and kept covered for additional 2 weeks. The cover was gradually removed during the following 2 weeks. For secondary hardening, rate response of antitranspirants $\mathrm{ABA}$ (7, 10 and $15 \mathrm{ppm})$ and glycerol (10,25 and 50\%) was studied (Table 5).

\subsection{Statistical analysis}

The data were subjected to Completely Randomized Design for statistical analysis.

\section{Results And Discussion}

\subsection{Shoot proliferation}

The explants recorded least time 4.34 days for culture establishment with highest establishment of 94.45 percent on MS medium supplemented with BAP $1.5 \mathrm{mg} / \mathrm{L}$ and malt extract $500 \mathrm{mg} / \mathrm{L}$ than all other treatments (Table 1 and Plate 1). Incorporation of NAA $(0.25 \mathrm{mg} / \mathrm{L})$ to BAP $1.0 \mathrm{mg} / \mathrm{L}$ and malt extract 500 $\mathrm{mg} / \mathrm{L}$ took more time (8.23 days) with less established cultures $(88.84 \%)$. Number of shoots and length of longest shoot per culture was also more in cultures supplemented with malt extract than BAP alone (Plate 1), whereas medium supplemented with BAP $1.0 \mathrm{mg} / \mathrm{L}$ + malt extract $500 \mathrm{mg} / \mathrm{L}$ + NAA $0.25 \mathrm{mg} / \mathrm{L}$ showed less number of shoots $(2.36)$ with minimum length $(1.17 \mathrm{~cm})$ of the longest shoot.. This increase in culture establishment in media supplemented with malt extract showed that malt extract is an ideal supplement and the most obligatory component as observed by earlier workers (Kochaba and Spiegel-Roy, 1973 [5]; Moore, 1985 [6]; Parthasarathy and Nagaraju, 1994 [7]; Das et al., 1995 [8]; Gloria et al., 2000 [9] and Chandra et al., 2003 [10]). However, endogenous levels of cytokinin and auxin play a very important role. Depending on the endogenous levels, requirement of the exogenous application vary to get the optimum responses. In this investigation reduction in the culture establishment percentage due to presence of auxin (NAA $0.25 \mathrm{mg} / \mathrm{L}$ ) indicated that endogenous level of auxin was near to optimum. Moreover, it is a specific auxin-cytokinin ratio which controls root and shoot formation in tissue culture (Engelke et al., 1973 [11]). Can et al. (1992) [12] also obtained shoot lets of trifoliate orange on medium containing IBA and NAA $(1.0 \mathrm{mg} / \mathrm{L})$ each.

\subsection{Effect of auxin concentration on rooting}

Root initiation from in vitro derived shoots of rough lemon started within 16-28 days (Table 2). The results indicated that half strength MS medium fortified with $1.0 \mathrm{mg} / \mathrm{L}$ NAA and IBA each was earlier (16.51 days) to show the root induction (Plate 2) with highest per cent rooting (83.33) than IBA and NAA $(1.0 \mathrm{mg} / \mathrm{L})$ alone. The control (which was devoid of hormones) treatment failed to produce in vitro rooting. Maximum number of roots per shoot (2.47) and length of longest root $(3.57 \mathrm{~cm})$ was observed in the medium supplemented with NAA and IBA $(1.0 \mathrm{mg} / \mathrm{L})$ each.

Improved rooting in lower strength media was attributed to reduction in nitrogen concentration (Hundman et al., 1982 [13]). The effect of IBA and NAA on rooting of micro shoots was found significant and synergetic. There was no rooting when none of the auxins were supplied to the media. Karwa (2003) [14] reported that MS medium lacking auxin showed very poor or no rooting which showed that exogenous application of auxin was necessary for rooting. NAA alone was also effective in rooting but to a less extent than the combination with IBA. Kim et al. (2002) [15] reported that MS media supplemented with $1.5 \mathrm{mg}$ L-1 NAA was most effective for root induction in Yooza mandarin. Ling et al. (2002) [16] and Chandra et al. (2003) [17] observed good root formation in the presence of auxins in the culture media.

\subsection{Effect of sucrose concentration on rooting}

MS medium supplemented with 3.0 per cent sucrose was earliest to initiate roots (14.96 days), while medium supplemented with 4.5 per cent was last to show root initiation (19.07 days) (Table 3 and Plate 3). Percentage of rooting ranged from 33.33 to 90.00 per cent, with maximum $(90.00 \%)$ rooting, number of roots $(2.24)$ and length of longest root $(3.39 \mathrm{~cm})$ in medium supplemented with 3.0 per cent sucrose, whereas increase in sucrose concentration 4.5 per cent suppressed in vitro root growth. The results are in consonance to Hazarika et al. (2004) [18]. Increase in sucrose concentration with decrease in salt concentration of media was found inhibitory to the root initiation and growth (Varidemoorele, 1993 [19]). Root formation required a low medium osmolarity but very low osmotic potential also had a negative effect on rooting. This may be the reason for lower response in medium supplemented with 1.5 and 4.5 per cent sucrose. 


\subsection{Effect of different potting mixtures on survival}

The maximum survival $(93.33 \%)$ was observed with potting mixture containing sand, soil and FYM in the ratio of (1:1:1), whereas plantlets in soil alone as substrate showed poor survival (Table 4 and Plate 4).

Physical, chemical and biological properties of the potting mixture are important for the establishment of in vitro produced plantlets. Better results of the mixture containing soil, sand and FYM (1:1:1) may be attributed due to performance of FYM to improve biological properties of the soil. Sand may be responsible for providing sufficient aeration. Rana and Singh (2002) [20] successfully established in vitro rooted shoots of Kagzi lime in sand, soil and compost (1:1:1) mixture.

\subsection{Effect of glycerol and ABA on survival}

The leaves of rooted plantlets treated with glycerol and ABA (Table 5) and it was found that glycerol was more effective than $\mathrm{ABA}$ as an antitranspirant for the hardening of plantlets of $C$. jambhiri. Maximum survival $(83.33 \%)$ was observed in the plantlets treated with 50 per cent glycerol, while control showed the least plant survival (22.21\%).

Among the antitranspirants tried, glycerol $50 \%$ was found to be the best as it resulted in maximum survival. Glycerol was proved to be most effective than ABA, which may be due to increase in the glycerol induced epicuticular wax content in the leaves (Mishra et al., 2005 [21]).

\section{Conclusions}

In vitro methods of reproducing the rootstock would ensure bulk production of true to type and disease free planting material. The protocol standardize for in vitro mass multiplication of Rough Lemon (Citrus jambhiri Lush.) was MS medium supplemented with BAP $(1.5 \mathrm{mg} / \mathrm{L})$ and malt extract $500 \mathrm{mg} / \mathrm{L}$ for maximum shoot proliferation. The in vitro multiplied shoots could be best rooted in half strength medium supplemented with IBA and NAA $(1.0 \mathrm{mg} / \mathrm{L})$ each with $3 \%$ sucrose as carbohydrate source. Hardening of in vitro formed plantlets was done in potting mixture containing sand, soil and FYM (1:1:1). Highest survival was achieved when rooted plantlet leaves were treated with $50 \%$ glycerol as an antitranspirant.

\section{References}

[1] Vij, V.K. and H. Kumar, 1990. Citrus rootstock selection, raising and performance in Citriculture in North-Western India. Edited by Gill K.S, Kanwar J.S. \& Singh R. (Punjab Agricultural University, Ludhiana, India), 126.

[2] Edriss, M.H. and D.W. Burger, 1984. In vitro propagation of 'Troyer' citrange from epicotyl segments. Scientia Hortic., $23: 159$.

[3] Ali, Shawkat and Bushra Mirza (2006) Micropropagation of rough lemon (Citrus jambhiri Lush.): Effect of explants type and hormone concentration. Acta Bot. Croat., 65(2): 137-146.

[4] Murashige, T. and F. Skoog, 1962. A revised medium for rapid growth and bioassays with tobacco tissue cultures. Physiol Plant, 15:473.

[5] Kochaba, J. and P. Spiegel-Roy, 1973. Effect of culture media on embryoid formation from ovular callus of 'Shamouti' orange. Zeit. Fur Pflanz., 69: 159

[6] Moore, G.A. 1985. Factor affecting in vitro embryogenesis from undeveloped ovules of mature citrus fruit. J. Amer. Soc. Hortic. Sci., 110: 66.

[7] Parthasarathy, V.A. and V. Nagaraju, 1994. Note on embryogenesis in ovules of Cleopatra mandarin (C. reticulata). Indian J Hortic., 51: 49.

[8] Das, T., G.C. Mitra and A. Chatterjee, 1995. Micropropagation of Citrus sinensis cv. Mosambi-An important scion. Phytomorphology, 45: 57.

[9] Gloria, F.J., M.M. Filho, F- de. A.A. Camargo and L.E.A. Mendes, 2000. Plant Regeneration from protoplast of Brazilian citrus cultivars. Époques Agropecuaria Brasileira, Brasilia, 35: 727-32.

[10] Chandra, A., V. Gupta, P. Burma and D. Pental, 2003. Patterns of morphogenesis from cotyledon explants of Citron (C. medica L.). In Vitro Cell and Dev. Biol., 39: 514-9.

[11] Engelke, A.I., H.Q. Hamzi and F. Skoog, 1973. Cytokinin-gibberellin regulation of shoot development and leaf form in tobacco plantlets. Amer. J. Bot., 60: 491.

[12] Can, C., N.K. Koc and A. Cinar 1992. In vitro clonal propagation of sour orange (C. aurantium var. Brezilia) by using epicotyl segments. Doga Turk Tarim Ve Ormancilik Dergisi, 16: 132.

[13] Hundman, S.E., P.M. Hasegawa and R.A. Bressan, 1982. Stimulation of root initiation from cultured rose shoots through the use of reduced concentrations of mineral salts. HortScience, 17: 82.

[14] Karwa, A. 2003. In vitro propagation of C. reticulata Blanco. (Nagpur mandarin). Indian J. Genetics Plant Breeding, 63: 187.

[15] Kim, M.H., H. Lee, M.S. Chung, J. Joo, 2002. Factor affecting efficiency of shoot induction in citrus junos. M.Sc. Thesis, National University, Daegu Korea

[16] Ling, Y.X., A. Kitajima, K. Hasegawa and X.L. Yang, 2002. Callus induction and embryoid regeneration from the endosperm culture of 'Tosa-Buntan' pummelo [C. grandis (L.) Osb.]. Environ. Control Biol., 38: 241-6

[17] Chandra, A., V. Gupta, P. Burma and D. Pental, 2003. Op. cit.

[18] Hazarika, B.N., V.A. Parthasarathy and V. Nagaraju 2004. Influence of in vitro preconditioning of Citrus spp. micro shoots with sucrose on their ex vitro establishment. Indian J. Hortic., 61: 29.

[19] Varidemoorele, J.L., J.P. Billar, J. Boucaud and T. Caspar 1993. Effect of Osmolarity and medium composition on callogenesis and rhizogenesis of Brassica oleracea L. var. Botrytis hypocotyls fragments. Biologia Plant., 35: 17.

[20] Rana, J.S. and R. Singh 2002. In vitro clonal propagation of Kagzi lime (Citrus aurantifolia Swingle) through shoot tips. Progressive Hortic., 34: 27.

[21] Mishra, A., R.K. Pandey and R.K. Gupta, 2005. Micro propagation of tuberose (Polianthes tuberosa L.) cv. Calcuttia double, Progressive Hortic., 37: 331. 


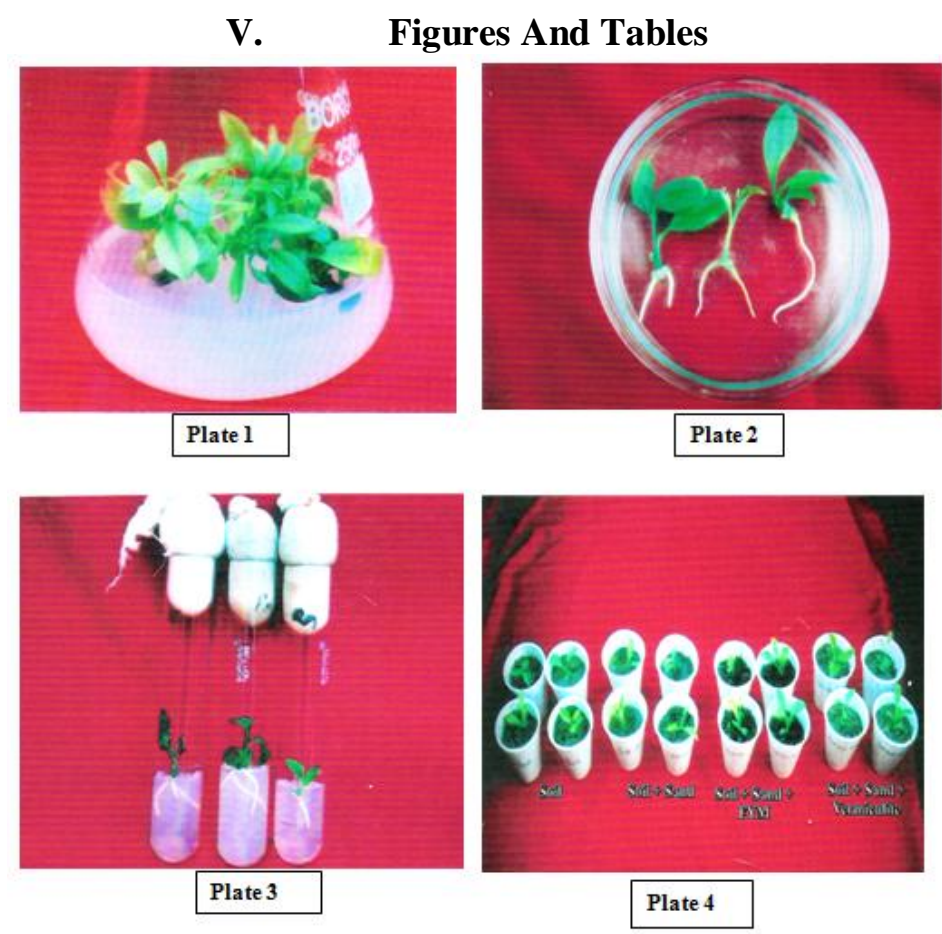

Table 1: Effect of different levels of BAP, NAA and malt extract on shoot proliferation of Citrus jambhiri Lush.

\begin{tabular}{|l|l|l|l|l|}
\hline Treatments $(\mathrm{mg} / \mathrm{L})$ & $\begin{array}{l}\text { Time taken for } \\
\text { culture establishment } \\
\text { (days) }\end{array}$ & $\begin{array}{l}\text { Culture } \\
\text { establishments }(\%)\end{array}$ & $\begin{array}{l}\text { No. of shoots per } \\
\text { culture }\end{array}$ & $\begin{array}{l}\text { Length of longest } \\
\text { shoot }(\mathrm{cm})\end{array}$ \\
\hline BAP(1.0mg/I) & 8.24 & $88.89(70.76)+$ & $3.88(2.21)^{++}$ & 1.89 \\
\hline BAP(1.5mg/I) & 7.12 & $91.96(76.36)$ & $4.41(2.33)$ & 1.39 \\
\hline $\begin{array}{l}\text { BAP(1.0mg/I)+ malt } \\
\text { extract 500(mg/L) }\end{array}$ & 6.48 & $91.67(76.36)$ & $4.50(2.35)$ & 2.31 \\
\hline $\begin{array}{l}\text { BAP }(1.5 \mathrm{mg} / \mathrm{I})+\text { malt } \\
\text { extract } 500(\mathrm{mg} / \mathrm{L})\end{array}$ & 4.34 & $94.45(78.80)$ & $5.34(2.52)$ & 1.96 \\
\hline $\begin{array}{l}\text { BAP }(1.0 \mathrm{mg} / \mathrm{I})+\mathrm{malt} \\
\text { extract } 500(\mathrm{mg} / \mathrm{L})+ \\
\text { NAA }(0.25 \mathrm{mg} / \mathrm{L})\end{array}$ & 8.23 & $88.89(70.76)$ & $2.36(1.83)$ & 1.17 \\
\hline C.D $(\mathrm{p}=0.05):$ & 0.22 & 8.24 & & 0.05 \\
\hline
\end{tabular}

Table 2: Effect of auxin concentration on in vitro rooting of Citrus jambhiri Lush.

\begin{tabular}{|l|l|l|l|l|}
\hline Treatments & $\begin{array}{l}\text { Root initiation } \\
\text { (days) }\end{array}$ & Rooting $(\%)$ & $\begin{array}{l}\text { No of root pre } \\
\text { shoot }\end{array}$ & $\begin{array}{l}\text { Length of } \\
\text { longest } \\
(\mathrm{cm})\end{array}$ \\
\hline IBA(1.0mg\I) & 29.80 & $53.33(46.90)^{+}$ & $1.62(1.62)++$ & 1.26 \\
\hline NAA $(1.0 \mathrm{mg} \backslash \mathrm{I})$ & 19.29 & $73.33(58.98)$ & $1.92(1.71)$ & 1.55 \\
\hline IBA(1.0mg\I)+NAA(1.0mg\) & 16.51 & $83.33(66.12)$ & $2.47(1.86)$ & 3.57 \\
\hline Control & 0.00 & $0.00(0.00)$ & $0.00(1.00)$ & 0.00 \\
\hline C.D $(\mathrm{p}=0.05):$ & 0.55 & 12.32 & 0.28 & 0.08 \\
\hline
\end{tabular}

Table 3: Effect of sucrose concentration on in vitro rooting of Citrus jambhiri Lush.

\begin{tabular}{|l|l|l|l|l|}
\hline $\begin{array}{l}\text { Sucrose } \\
\text { concentration (\%) }\end{array}$ & $\begin{array}{l}\text { Root initiation } \\
\text { (days) }\end{array}$ & Rooting $(\%)$ & $\begin{array}{l}\text { No. of root per } \\
\text { shoot }\end{array}$ & $\begin{array}{l}\text { Length of longest } \\
\text { root }(\mathrm{cm})\end{array}$ \\
\hline 1.5 & 17.50 & $53.33(46.90)+$ & $1.80(1.67)++$ & 2.29 \\
\hline 3.0 & 14.96 & $90.00(74.98)$ & $2.24(1.80)$ & 3.30 \\
\hline 4.5 & 19.07 & $33.33(35.20)$ & $1.50(1.58)$ & 2.39 \\
\hline C.D.(p-0.05) : & 0.33 & 16.99 & 0.10 & 0.60 \\
\hline
\end{tabular}


Table 4: Effect of different potting mixture on survival of rooted plantlets of Citrus jambhiri Lush.

\begin{tabular}{|l|l|}
\hline Treatments & Survival(\%) \\
\hline Soil & $73.33(58.98)+$ \\
\hline Soil+ sand (1:1) & $76.66(61.20)$ \\
\hline Soil + sand + FYM (1:1:1) & $93.33(77.69)$ \\
\hline Soil + sand + vermiculite $(1: 1: 1)$ & $83.33(66.12)$ \\
Soil + sand + vermiculite $(1: 1: 1)$ & \\
\hline C.D. $(\mathrm{p}=0.05)$ & 12.83 \\
\hline
\end{tabular}

Table 5: Effect of Glycerol and ABA on survival of Citrus jambhiri Lush. plantlets

\begin{tabular}{|l|l|}
\hline Treatments & Survival $(\%)$ \\
\hline Glycerol $(10 \%)$ & $38.87(38.48)$ \\
\hline Glycerol $(25 \%)$ & $55.56(48.23)$ \\
\hline Glycerol $(50 \%)$ & $83.33(70.20)$ \\
\hline ABA $(7 \mathrm{ppm})$ & $33.33(34.77)$ \\
\hline ABA $(10 \mathrm{ppm})$ & $27.76(31.52)$ \\
\hline ABA $(15 \mathrm{ppm})$ & $38.87(3 . .48)$ \\
\hline Control & $22.21(27.80)$ \\
\hline C.D. $(\mathrm{p}=0.05)$ & 16.54 \\
\hline
\end{tabular}

